\title{
Rockburst Disaster Prediction of Isolated Coal Pillar by Electromagnetic Radiation Based on Frictional Effect
}

\author{
Tongbin Zhao, ${ }^{1,2,3}$ Yanchun Yin, ${ }^{1,3}$ Fukun Xiao, ${ }^{2}$ Yunliang Tan, ${ }^{1,3}$ and Jianchao Zou ${ }^{3}$ \\ ${ }^{1}$ State Key Laboratory Breeding Base for Mining Disaster Prevention and Control, Shandong University of Science and Technology, \\ Qingdao, Shandong 266590, China \\ ${ }^{2}$ Heilongjiang Ground Pressure \& Gas Control in Deep Mining Key Lab, Heilongjiang University of Science and Technology, Harbin, \\ Heilongjiang 150027, China \\ ${ }^{3}$ College of Mining and Safety Engineering, Shandong University of Science and Technology, Qingdao, Shandong 266590, China
}

Correspondence should be addressed to Yanchun Yin; yycrsd@163.com

Received 15 April 2014; Accepted 4 June 2014; Published 18 June 2014

Academic Editor: Abdelghani Bellouquid

Copyright (C) 2014 Tongbin Zhao et al. This is an open access article distributed under the Creative Commons Attribution License, which permits unrestricted use, distribution, and reproduction in any medium, provided the original work is properly cited.

\begin{abstract}
Based on the understanding that charges generated during coal cracking are due to coal particle friction, a microstructure model was developed by considering four different variation laws of friction coefficient. Firstly, the frictional energy release of coal sample during uniaxial compressive tests was investigated and discussed. Then electromagnetic radiation method was used to predict the potential rockburst disaster in isolated coal pillar mining face, Muchengjian Colliery. The results indicate that the friction coefficient of coal particles decreases linearly with the increase of axial loading force. In predicting the strain-type rockburst, the high stress state of coal must be closely monitored. Field monitoring shows that electromagnetic radiation signal became abnormal before the occurrence of rockburst during isolated coal pillar mining. Furthermore, rockburst tends to occur at the early and ending stages of isolated coal pillar extraction. Mine-site investigation shows the occurrence zone of rockburst is consistent with the prediction, proving the reliability of the electromagnetic radiation method to predict strain-type rockburst disaster.
\end{abstract}

\section{Introduction}

The electromagnetic radiation occurs with the crack of rock under stress loading. The emission of this energy signal has been taken as the early warning of seismic activities [13]. In recent years, significant progress has been achieved in the aspects of physical mechanism, signal characteristics, early warning identification, and monitoring equipment of electromagnetic radiation. So far, it has been successfully applied to analyze regional high stress and monitor engineering disasters, such as rockburst and coal and gas burst. Typical work can be seen from the research work of He et al. and Wang et al. [4-6]. In uniaxial compressive tests, the coal sample fails due to aggressively developed cracks caused by the increase of uniaxial compressive stress. The crack growth and the emergence of new cracks reflect the sudden release of accumulated strain energy. From this perspective, the failure of coal can be seen as the complicated process of the growth of existing crack and emergence of new cracks. Laboratory study shows that charges generated from particle friction contribute to the occurrence of electromagnetic radiation for coal under axial loading [7].

The macro- and microfriction studies are an important part of rock mechanics. Since 1950s, the studies of frictional effect mainly concentrated on the mechanical interface behavior of rock joint or fault. The studies of China University of Mining Technology significantly advanced the understanding of electromagnetic radiation caused by friction of coal $[7,8]$. The study of frictional effect among damaged coal particles can accurately reveal the mechanism of electromagnetic radiation. However, due to the limitation of experimental methods and equipment, the physical study on the friction among coal particles on the microscale is difficult. Instead, numerical experiments can be an effective way to bridge this gap.

The aim of this study is to provide theoretical guidance and foundations for the application of electromagnetic radiation method in predicting rockburst of coal mines. In detail, 


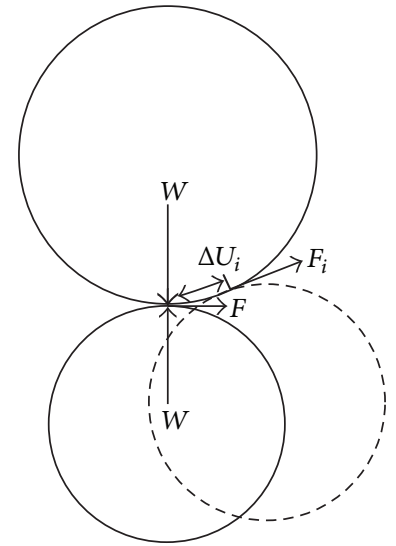

Figure 1: Friction between particle balls.

starting from viewport that friction among coal particles can generate charges and hence emit electromagnetic signals, the release of frictional energy during uniaxial compressive loading was investigated using the microparticle flow codePFC. Later on, the prediction accuracy of electromagnetic radiation was estimated by applying it to predict the rockburst during isolated coal pillar extraction.

\section{Frictional Energy Release of Coal in Loading}

2.1. Friction Law among Coal Particles. The coal is the aggregation of mineral particles and its internal friction can be considered as the relative slip among particles. Assuming that two particle balls are in contact at one point under the action of force $W$ normal to contact plane (see Figure 1), the shear force $F$ required for relative slip between two balls can be given by

$$
F=\mu W
$$

where $W$ is normal force between coal particles, $F$ is the shear force resulting in relative slip among particles, and $\mu$ is friction coefficient.

Amonton law states that friction coefficient $\mu$ only relates with the material, roughness, and state of contact plane, irrespective of normal force $W$. However, for coal, it has been proved that its friction coefficient $\mu$ is not invariable but changes with the normal force $W$; that is, $\mu=f(W)$. In general, it decreases with the increase in normal force $W$ [9$12]$.

The action of shear force on particle yields relative slip. The energy dissipated can be defined as frictional energy. If the number of contact points within a coal sample is $m$ and the number of damaged contact points is $n$ under external loading, the dissipated frictional energy at the instant $t$ can be calculated by

$$
E_{f}=\sum_{i=1}^{n} F_{i} \Delta U_{i}
$$

where $F_{i}$ is shear force at the $i$ th contact point, $\Delta U_{i}$ is the resultant slip displacement at the $i$ th damaged contact point
TABLE 1: Parameters of microstructure model.

\begin{tabular}{lccc}
\hline $\begin{array}{l}\text { Particle radius } \\
/ \mathrm{mm}\end{array}$ & $\begin{array}{c}\text { Density } \\
/ \mathrm{kg} \cdot \mathrm{m}^{-3}\end{array}$ & $\begin{array}{c}\text { Young's modulus } \\
/ \mathrm{GPa}\end{array}$ & $\begin{array}{c}\text { Cohesive strength } \\
/ \mathrm{MPa}\end{array}$ \\
\hline $0.2 \sim 0.3$ & 2000 & 5 & 20 \\
\hline
\end{tabular}

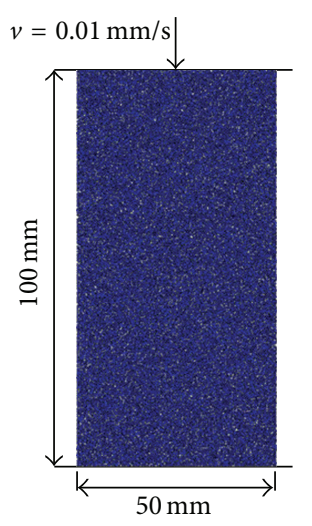

FIGURE 2: Generated model for uniaxial compressive test.

comparative to the state at last considered moment $t-\Delta t$, and $E_{f}$ is the released frictional energy at the instant $t$.

Equations (1) and (2) indicate that the released frictional energy correlates with normal force of particles, slip distance, and intrinsic property of contact point. The $W$ and $\Delta U_{i}$ are easy to measure; however, the friction coefficient $\mu$ is comparatively difficult to determine.

2.2. Micromodel Development of Coal Particle Flow. The model of uniaxial compressive tests was developed using the PFC and shown in Figure 2. The dimension of the model is $100 \times 50 \mathrm{~mm}$. In simulation, the axial loading was realized by applying a velocity of $0.01 \mathrm{~mm} / \mathrm{s}$ at the top of the developed model. The physical and mechanical parameters of the model are summarized in Table 1 . In computation during uniaxial loading, the stress, strain, crack, and frictional energy are monitored using in-built fish programming language.

In order to study the influence of the friction coefficient on the frictional energy release before peak strength of coal sample, four different variation laws of friction coefficient were designed in the numerical modeling, where the mathematical expectation is 0.6: (1) method 1-the friction coefficient is a constant; (2) method 2-the friction coefficient increases linearly with the increase of axial loading; (3) method 3-the friction coefficient decreases linearly with the increase of axial loading, and (4) method 4-the friction coefficient decreases exponentially with the increase of axial loading. Figure 3 shows these four change profiles of friction coefficient with the increase in axial loading.

2.3. Results Analysis. Figure 4 shows the computerized results using different friction coefficient variation laws. At the comparative low stress-strain phase, the monotonous increase trend of released frictional energy is attributed to particle compaction or friction resistance between particles and boundary. It is not within the scope of this study and 


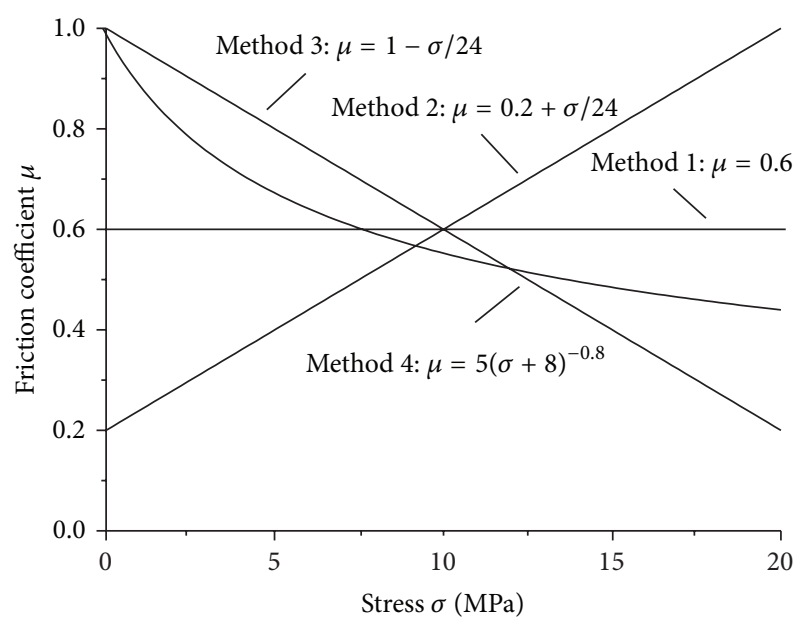

FIGURE 3: Choosing methods of the friction coefficient.

is not discussed further. When the accumulated deformation of coal sample approached a certain value, the shear slip among internal particles of coal caused the release of frictional energy and the amount of released frictional energy increased before meeting the peak strength of coal sample. By comparison, it can be seen from Figure 4 that the frictional energy of method 3 generates constantly and obviously in the loading process, which is in better accordance with the laboratory test result of electromagnetic radiation (Figure 5). Hence, the correct characterization of friction coefficient is crucial for accurate description of electromagnetic radiation energy caused by friction.

Using the computation result of method 3, the internal relation between frictional energy and cohesive damage among coal particles is discussed here (Figure 6). The release of frictional energy and the emergence of crack occurred at the same time, indicating that the energy of electromagnetic radiation comes from the damage slip among coal particles. Before the peak strength, the released frictional energy increased with the crack, and the release of accumulated frictional energy is exponentially proportional to the accumulated cracks. Under the control of decreasing friction coefficient, the release of frictional energy becomes slow before failure of the coal sample. Hence, the computational result of method 3 is consistent with laboratory electromagnetic radiation experiment during uniaxial compressive loading on coal samples. This provides a more proper explanation for application of electromagnetic radiation method in predicting high stress state of coal seam.

\section{Mechanism of Electromagnetic Radiation in Predicting Strain-Type Rockburst}

3.1. Electromagnetic Radiation Characteristics of Coal under Compressive Loading. Xiao et al. [13] recorded the electromagnetic radiation signal while conducting uniaxial compressive test on the coal sample and established the correlation between the compressive stress and the intensity of electromagnetic radiation as shown in Figure 5. It can be seen that at the initial stage of axial loading, the amplitude of the electromagnetic radiation signal increases with the loading before approaching the peak strength of coal sample. However, after reaching peak strength of coal sample, the signal amplitude decreases with further increase in axial loading.

On the microscale, these generated charges during coal cracking come from the charge separation. The charges from the electric double layer cannot disappear in time during the coal cracking and separated subsequently. At the loading phase before reaching peak strength of coal sample, the dominant part of the electric charges is generated by coal particle friction and the captured electromagnetic signal is very strong. Hence, frictional effect can reasonably explain this resultant electromagnetic radiation phenomenon.

3.2. Electromagnetic Radiation Method in Monitoring Stress of Surrounding Rock. The electromagnetic radiation monitoring system mainly consists of computer, receiving transducer, transform port, and connecting cable. It has the characteristics of noncontact, regional, continuous monitoring. The main monitoring indicators are amplitude intensity and pulse number.

In application to monitor electromagnetic radiation signals of country rock in mining, noncontactable inductance type wideband directional receiving probe is usually used. The distance between the monitoring apparatus and the targeted mining wall is usually set in the range of $0.6-1.0 \mathrm{~m}$ and the internal among monitoring points is approximately $10 \mathrm{~m}$. The effectiveness monitoring depth can be $7-22 \mathrm{~m}$ within the coal ore. The layout of the electromagnetic radiation monitoring positions is shown in Figure 7. The signals of electromagnetic radiation were recorded according to the number sequence of monitoring positions. The monitoring time for each point is $180 \mathrm{~s}$.

3.3. Mechanism of Electromagnetic Radiation Method to Predict Strain-Type Rockburst. The rockburst has been one of the major engineering disasters perplexing the coal mining industry. There are still some disagreements on its deciding factor, physical mechanism, and prediction techniques [1417]. Recently, the 973 research team on the project of "study on dynamic disaster mechanism and prevention of coal in deep mining" categorized the rockburst into three types: straintype, slip-type, and mix-type. This categorization is of more significance for rockburst prediction and prevention.

The radical reason for the strain-type rockburst is due to high stress concentration caused by mining activities. Also, the strength of coal seam is usually lower than surrounding rock and the exposed working face also provides the essential space of such energy release. With the advance of mining extraction, elastic strain energy gradually accumulates in front coal body of mining face. When such accumulated elastic energy reaches its critical value, further engineering disturbance will trigger rockburst $[18,19]$. Different from sliptype rockburst, the high abutment stress should be closely 


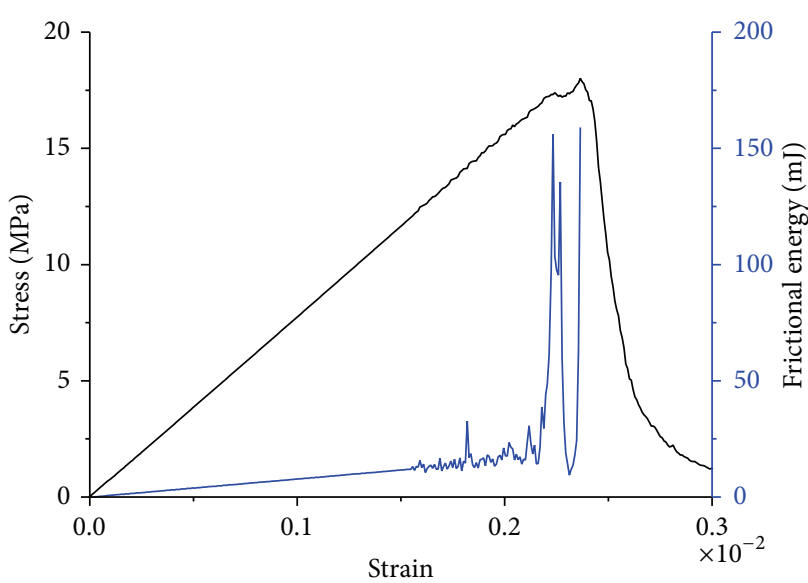

(a)

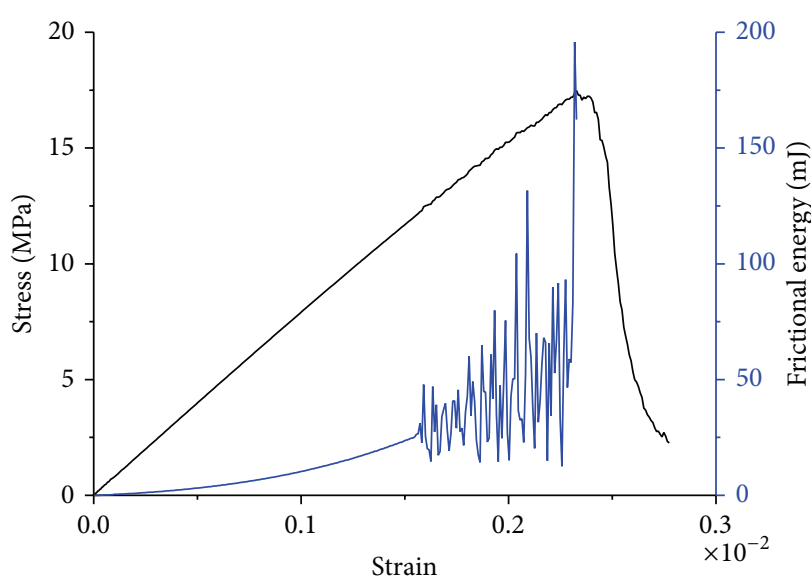

(c)

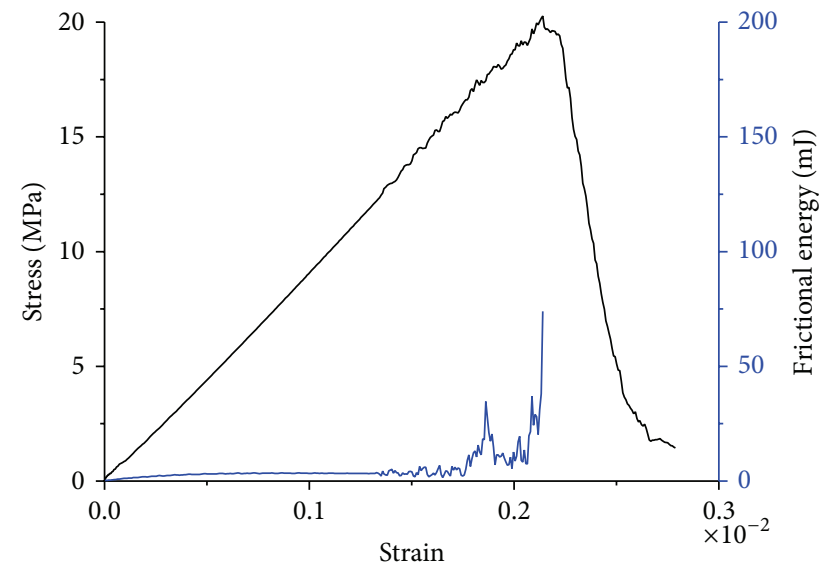

(b)

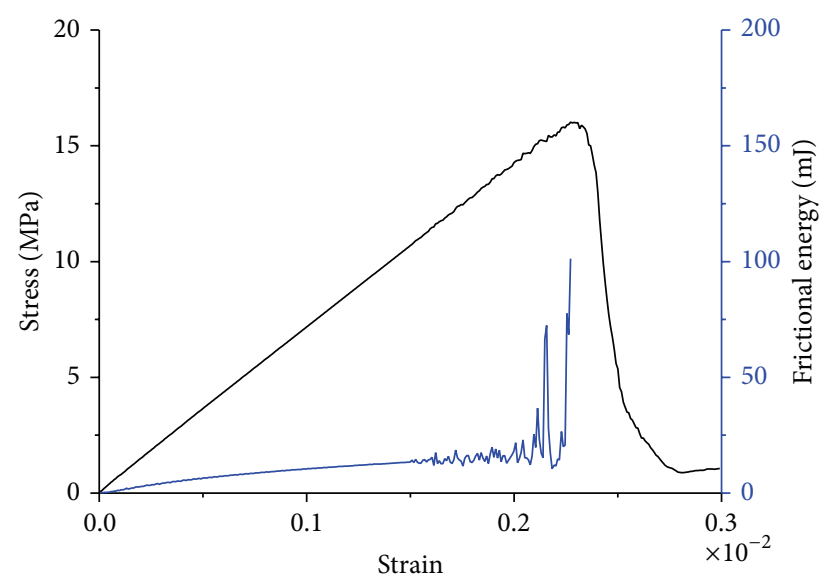

(d)

Figure 4: Frictional energy and stress curves of different methods. (a) Method 1; (b) method 2; (c) method 3; and (d) method 4.

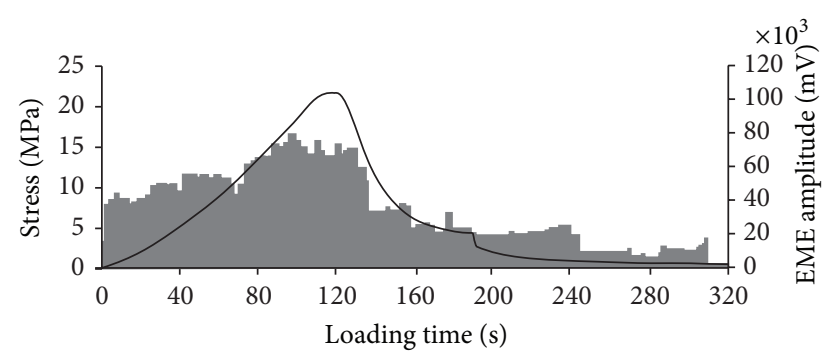

Figure 5: Curves of stress and electromagnetic amplitude.

monitoring in predicting strain-type rockburst $[20,21]$. Isolated coal pillar mining is one of the typical engineering situations with strain-type rockburst (see Figure 8).

The strain-type rockburst usually occurs in high stress zone of abutment pressure in mining. According to the frictional effect study presented above, the cracks within this zone grow with the mining face advance and the intensity of electromagnetic radiation signal becomes high.

\section{Application in Predicting Rockburst during Isolated Coal Pillar Extraction}

4.1. Field Geological Conditions. Field prediction was conducted in an isolated working face located at $+250 \mathrm{~m}$ level in Mu-cheng-jian coal mine, West Beijing Area, China. The four sides of this working face were already stopped out. The dip length of the working face is $154 \mathrm{~m}$ while the strike length is $176 \mathrm{~m}$. At the early stage of mining in this working face, the monitoring positions are set in the upper and down gate road and the interval distance among monitoring points is $10 \mathrm{~m}$. With the advance of extraction, the monitoring points reduced while new monitoring points in the main upper gate road were set as shown in Figure 9.

4.2. Monitoring Result Analysis. The monitored result of electromagnetic radiation at the early stage of extraction is shown in Figure 10. It can be seen that the amplitude of electromagnetic radiation in down gate road is obviously higher than that in upper gate road, especially in the zone within monitoring points $7-8$. That is within the range of $40 \mathrm{~m}$ in front of mining face. This indicates that the down gate 


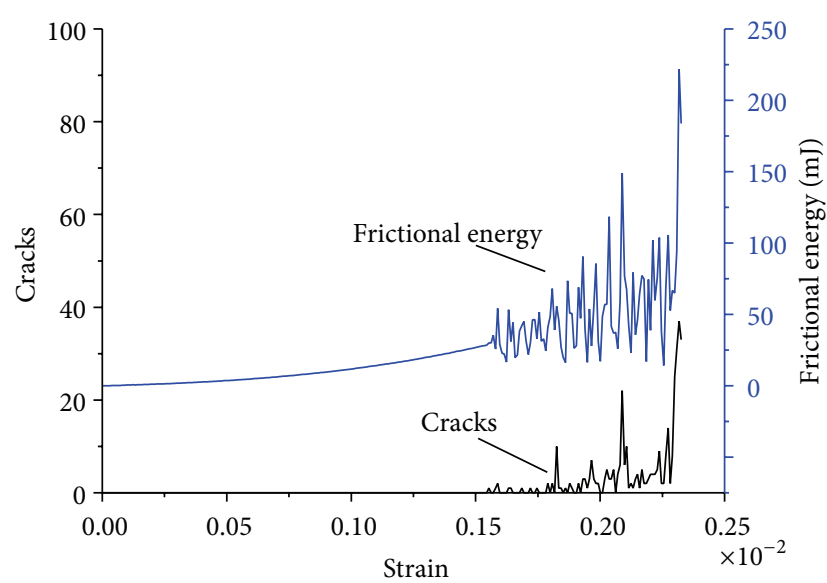

(a)

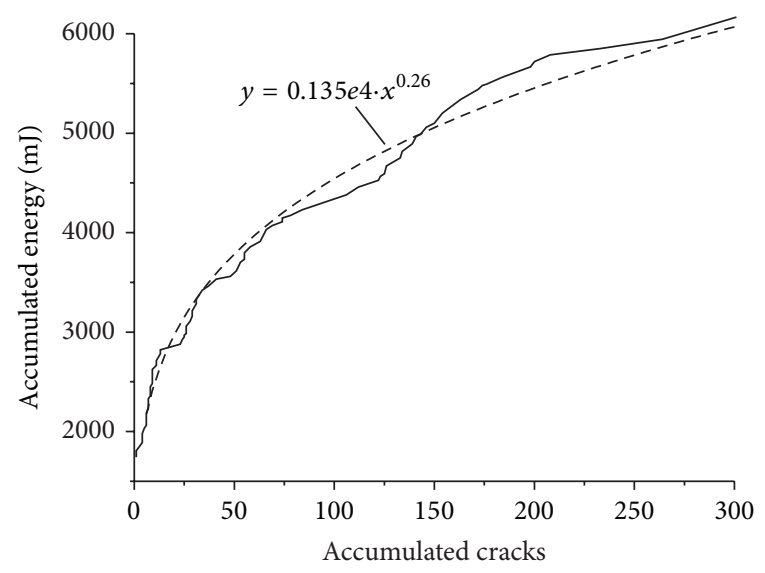

(b)

FIGURE 6: Relation curves of frictional energy and cracks. (a) Transient energy and cracks; (b) accumulated energy and cracks.

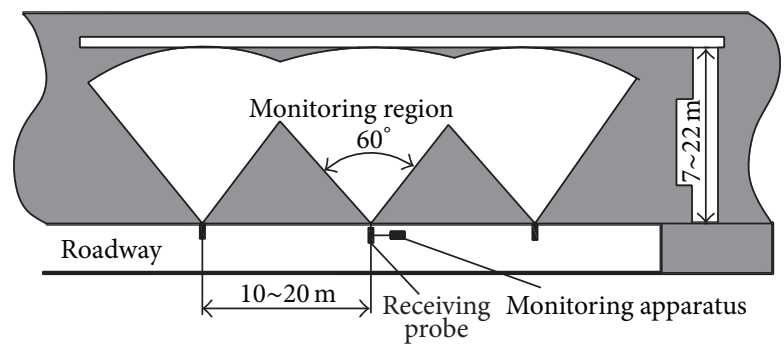

FIGURE 7: Monitoring region of electromagnetic radiation [7].

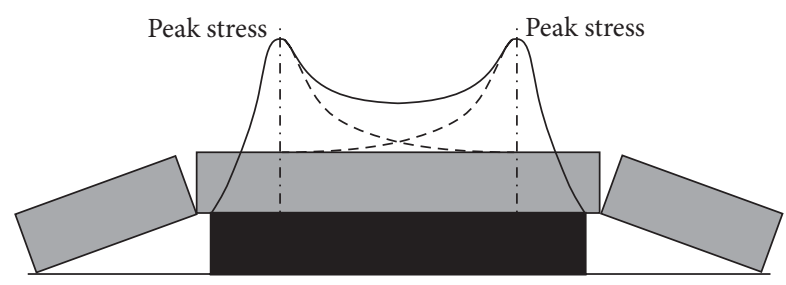

FIGURE 8: Abutment pressure distribution of the coal pillar.

road is under high stress concentration conditions. When the working face advanced the $30 \mathrm{~m}$, one rockburst occurred. Figure 11 shows the locality of this rockburst disaster. It can be seen that the actual place of the rockburst is almost the same with that by electromagnetic radiation prediction.

The high stress is due to stress superposition caused by extraction in the four sides of this working face. What is more, there is a stress concentration in advance heading. Such high stress must be relieved in time with the blasting presplitting method. Otherwise it can trigger rockburst disaster.

When advancing to $40 \mathrm{~m}$ of upper gate road, the monitored result of electromagnetic radiation is shown in Figure 12. The signal of electromagnetic radiation becomes abnormally high at the intersection of main gate road and two gateways, that is, monitoring points $4-6$ and $14-16$, indicating the existence of a triangular-shaped high stress concentration zone. Consistent with the prediction, the actual rockburst occurred in the locality as shown Figure 13.

At the ending phase of extraction, the unmined coal pillar becomes smaller and internal stress hence becomes higher. The formation of high stress concentration becomes easier in front abutment pressure zone. Rockburst occurs when the accumulated elastic energy becomes high enough. This is the reason for the occurrence of rockburst when the left unmined zone is of the size $55 \times 48 \mathrm{~m}$.

\section{Conclusions}

Numerical simulation based on microparticle flow code shows that uniaxial loading cracked the cohesion among coal particles and caused frictional energy release. Also, it is found that the frictional energy release law is in better accordance with the laboratory experiments of electromagnetic radiation when the friction coefficient decreases linearly with the increase of compressive loading. This provides a fundamental guidance for the application of electromagnetic radiation method to monitor high stress state of surrounding rock during coal mining.

Strain-type rockburst typically occurs in the process of isolated coal pillar extraction. Field applications show that the signals of electromagnetic radiation became obviously abnormal before the occurrence of rockburst, and also the rockburst tends to occur easily at the early and ending stages of isolated coal pillar extraction. The effectiveness of electromagnetic radiation method to predict strain-type rockburst is proved as the actual occurrence zones of rockburst are in good agreement with prediction.

In practice, one of essential conditions for occurrence of strain-type rockburst is high stress concentration and hence the prediction should mainly focus on the monitoring of high stress state. As the electromagnetic radiation monitoring can timely reflect the stress state of coal ore, together with its noncontact and regional monitoring characteristics, it is an effective technique to predict strain-type rockburst. 


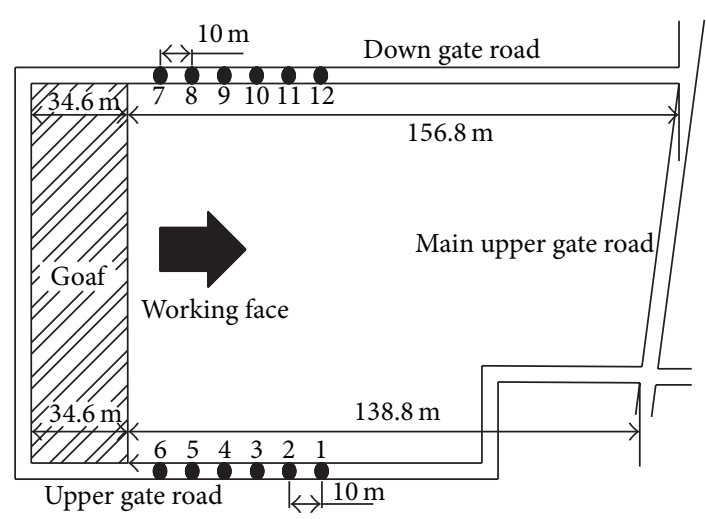

(a)

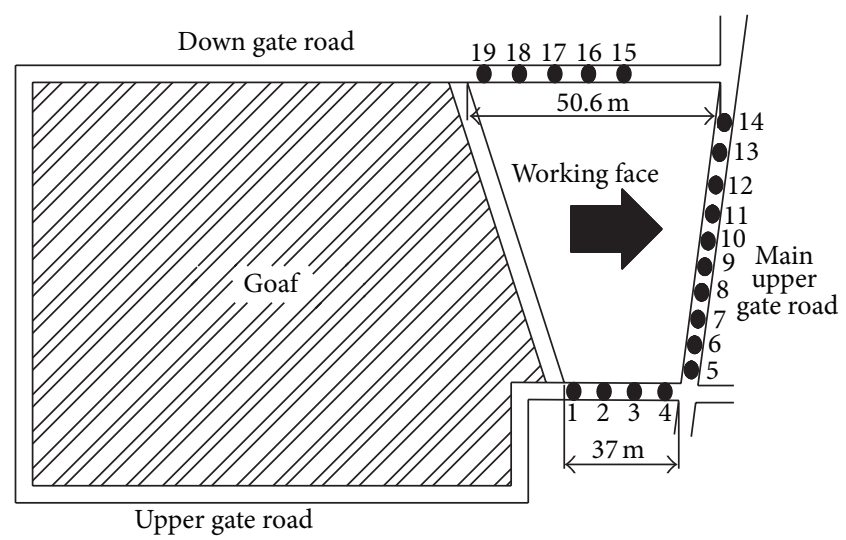

(b)

FIGURE 9: Monitoring disposal around coalface at the (a) early and (b) final stage of extraction.

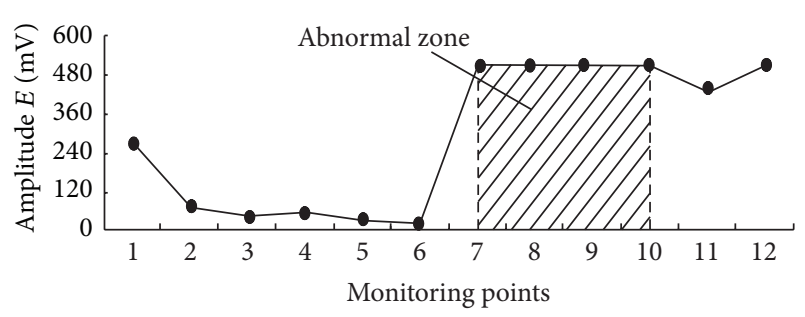

FIGURE 10: Electromagnetic radiation monitoring results at the early stage of extraction.

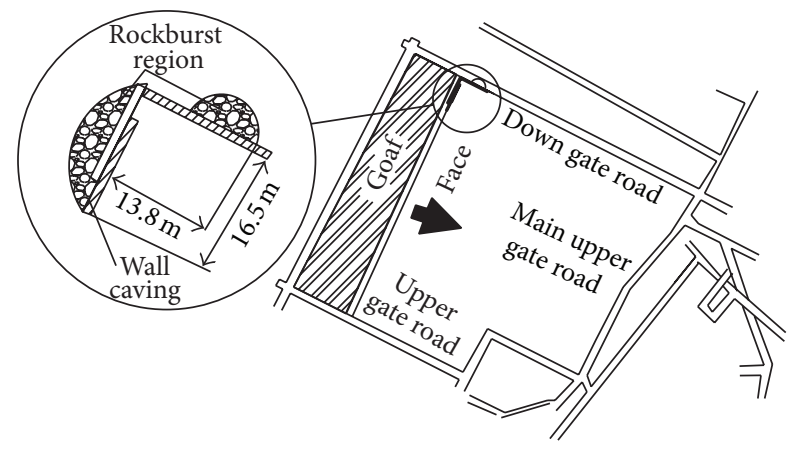

FIGURE 11: Rockburst region at the early stage of the extraction.

It is noteworthy that the correlation between the released frictional energy of coal particles and electromagnetic radiation was proposed based on the micronumerical simulation here. Future work will focus on further revelation of prediction mechanism of strain-type rockburst by experimental and theoretical studies.

\section{Conflict of Interests}

The authors declare that there is no conflict of interests regarding the publication of this paper.

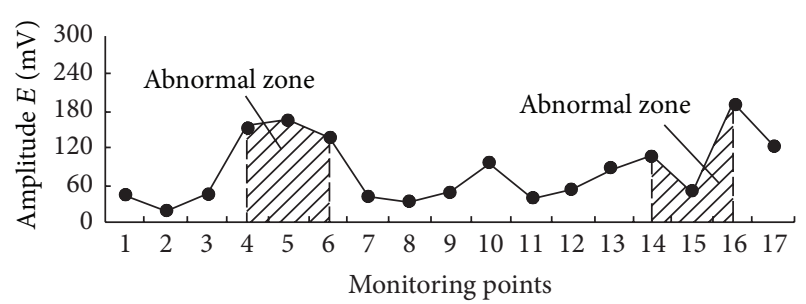

FIGURE 12: Electromagnetic radiation monitoring results at the final stage of extraction.

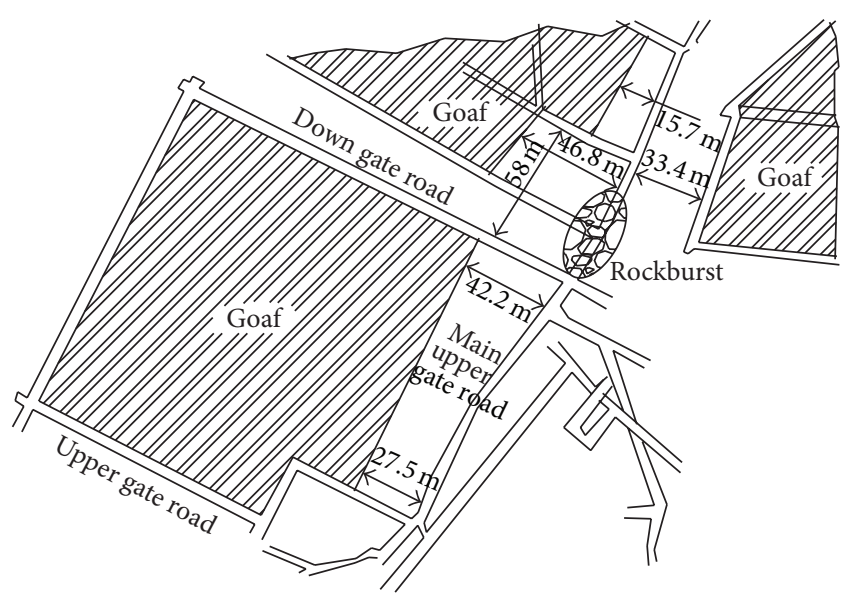

FIGURE 13: Rockburst region at the ending stage of the extraction.

\section{Acknowledgments}

This research is supported by National Natural Science Foundation of China (51274133), Open Fund Project of Heilongjiang Ground Pressure \& Gas Control in Deep Mining Key Lab (F2313-09), Fund for Distinguished Young Scholars of Shandong University of Science and Technology (2011KYJQ106), and Shandong Taishan Scholar Construction funds. 


\section{References}

[1] S. Q. Qian, K. X. Ren, and Z. Lv, "Experimental study of the feature of VLF, MF, HF and VHF electromagnetic radiation accompanying rock fracture," Aca Seismologica Sinica, vol. 18, no. 3, pp. 346-351, 1996.

[2] D. Song, E. Wang, and J. Liu, "Relationship between EMR and dissipated energy of coal rock mass during cyclic loading process," Safety Science, vol. 50, no. 4, pp. 751-760, 2012.

[3] V. Frid and K. Vozoff, "Electromagnetic radiation induced by mining rock failure," International Journal of Coal Geology, vol. 64, no. 1-2, pp. 57-65, 2005.

[4] E.-Y. Wang and E.-L. Zhao, "Numerical simulation of electromagnetic radiation caused by coal/rock deformation and failure," International Journal of Rock Mechanics and Mining Sciences, vol. 57, pp. 57-63, 2013.

[5] X. He, B. Nie, W. Chen et al., "Research progress on electromagnetic radiation in gas-containing coal and rock fracture and its applications," Safety Science, vol. 50, no. 4, pp. 728-735, 2012.

[6] E. Wang, X. He, X. Liu, and W. Xu, "Comprehensive monitoring technique based on electromagnetic radiation and its applications to mine pressure," Safety Science, vol. 50, no. 4, pp. 885893, 2012

[7] X. Q. He, E. Y. Wang, and B. S. Nie, Electromagnetic Dynamics of Coal or Rock Rheology, Science Press, Beijing, China, 2003.

[8] Y.-L. Yang, Z.-H. Li, E.-Y. Wang, Y.-F. Zhu, J. Liu, and X.-L. Li, "Experiment study on surface potential characteristics and rules during coal or rock friction process," Journal of the China Coal Society, vol. 38, no. 2, pp. 215-220, 2013.

[9] J. C. Jaeger and N. G. W. Cook, Fundamentals of Rock Mechanics, Science Press, Beijing, China, 1981.

[10] X. Qi, Y. W. Shi, and T. Q. Liu, "Mechanism of instability caused by viscous sliding in rock burst," Journal of China Coal Society, vol. 22, no. 2, pp. 144-148, 1997.

[11] L. P. Li, Y. S. Pan, S. L. Ma, and L. Q. Liu, "Experimental research into effect of ultra-low friction of rock mass in deep mining," Journal of Mining \& Safety Engineering, vol. 25, no. 2, pp. 164$167,2008$.

[12] Q.-P. Xu, Y.-S. Lu, and D.-R. Wang, "Experimental study on friction weakened effect of deep block rock mass," Journal of PLA University of Science and Technology (Natural Science Edition), vol. 10, no. 3, pp. 285-289, 2009.

[13] H.-F. Xiao, X.-Q. He, and E.-Y. Wang, "Research on transition law between EME and energy during deformation and fracture of coal or rock under compression," Rock and Soil Mechanics, vol. 27, no. 7, pp. 1097-1100, 2006.

[14] L. Wang, Z. Lu, and Q. Gao, "A numerical study of rock burst development and strain energy release," International Journal of Mining Science and Technology, vol. 22, no. 5, pp. 675-680, 2012.

[15] V. A. Mansurov, "Prediction of rockbursts by analysis of induced seismicity data," International Journal of Rock Mechanics and Mining Sciences, vol. 38, no. 6, pp. 893-901, 2001.

[16] T.-B. Zhao, Y.-L. Tan, and Z. Zhang, "Geomechanical mechanism of rock burst in deep level of Datai Mine," Journal of the China Coal Society, vol. 35, no. 12, pp. 2039-2044, 2010.

[17] Y.-L. Tan, Z. Zhang, and T.-B. Zhao, "AE pattern of rock burst disaster induced by strata activation in coal mine," Disaster Advances, vol. 4, no. 4, pp. 29-33, 2011.

[18] X. Feng, B. Chen, H. Ming et al., "Evolution law and mechanism of rockbursts in deep tunnels: immediate rockburst," Chinese Journal of Rock Mechanics and Engineering, vol. 31, no. 3, pp. 433-444, 2012.
[19] P.-X. Fan, M.-Y. Wang, S.-L. Yue, and C.-Y. Shi, "Review on the evolution law, mechanics and prevention of strain rockburst," Journal of Wuhan University of Technology, vol. 35, no. 4, pp. 96-101, 2013.

[20] R. F. Poplawski, "Seismic parameters and rockburst hazard at Mt Charlotte mine," International Journal of Rock Mechanics and Mining Sciences, vol. 34, no. 8, pp. 1213-1228, 1997.

[21] H.-W. Wang, Y.-D. Jiang, Z.-D. Yang, and S. Liu, "Multi-variable assessment of coal bump risk during extraction of an island longwall panel," Journal of the China Coal Society, vol. 37, no. 11, pp. 1790-1795, 2012. 

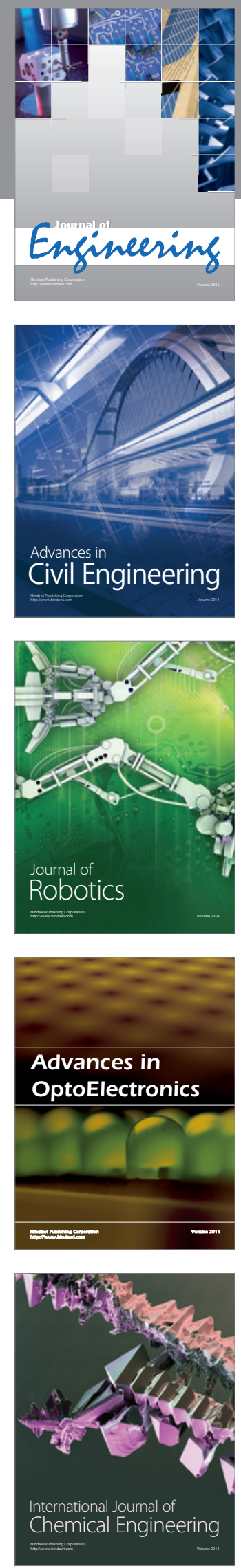

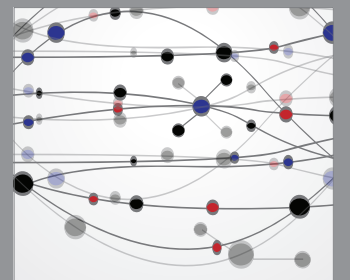

The Scientific World Journal
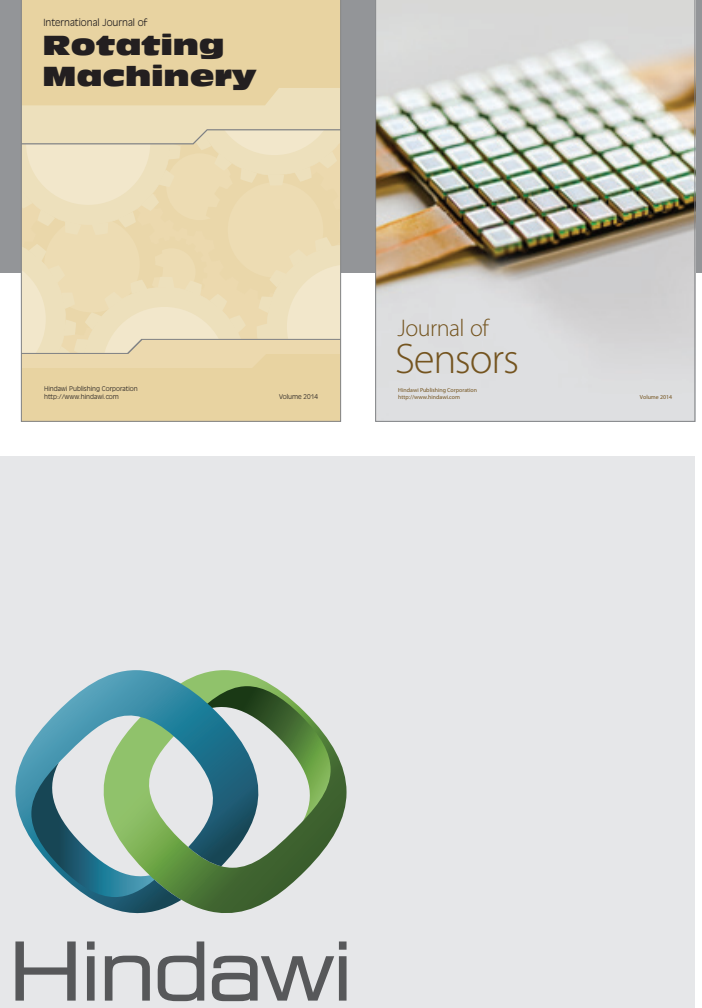

Submit your manuscripts at http://www.hindawi.com
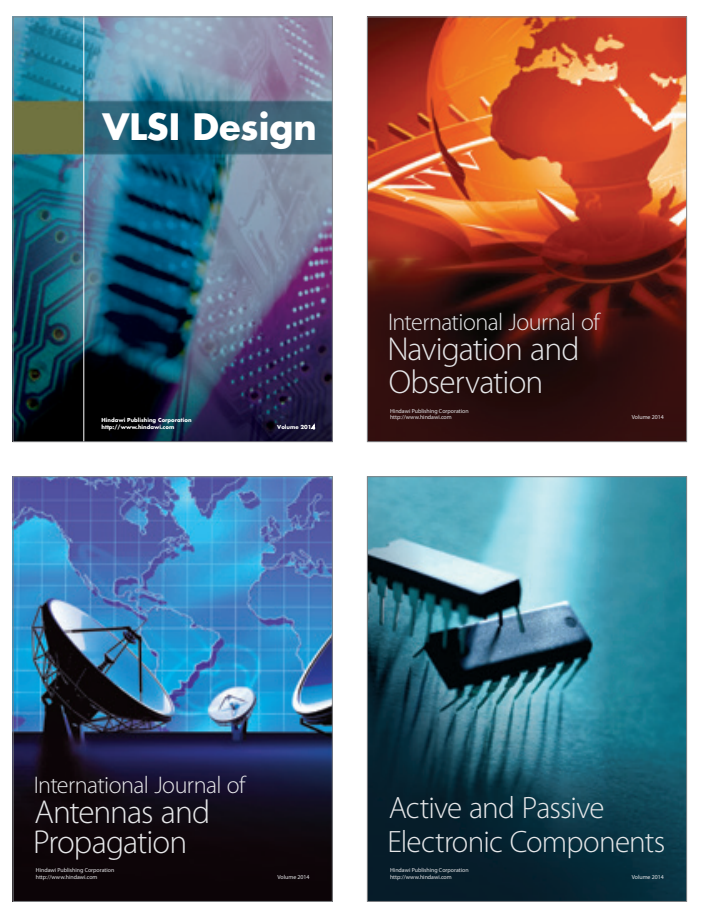
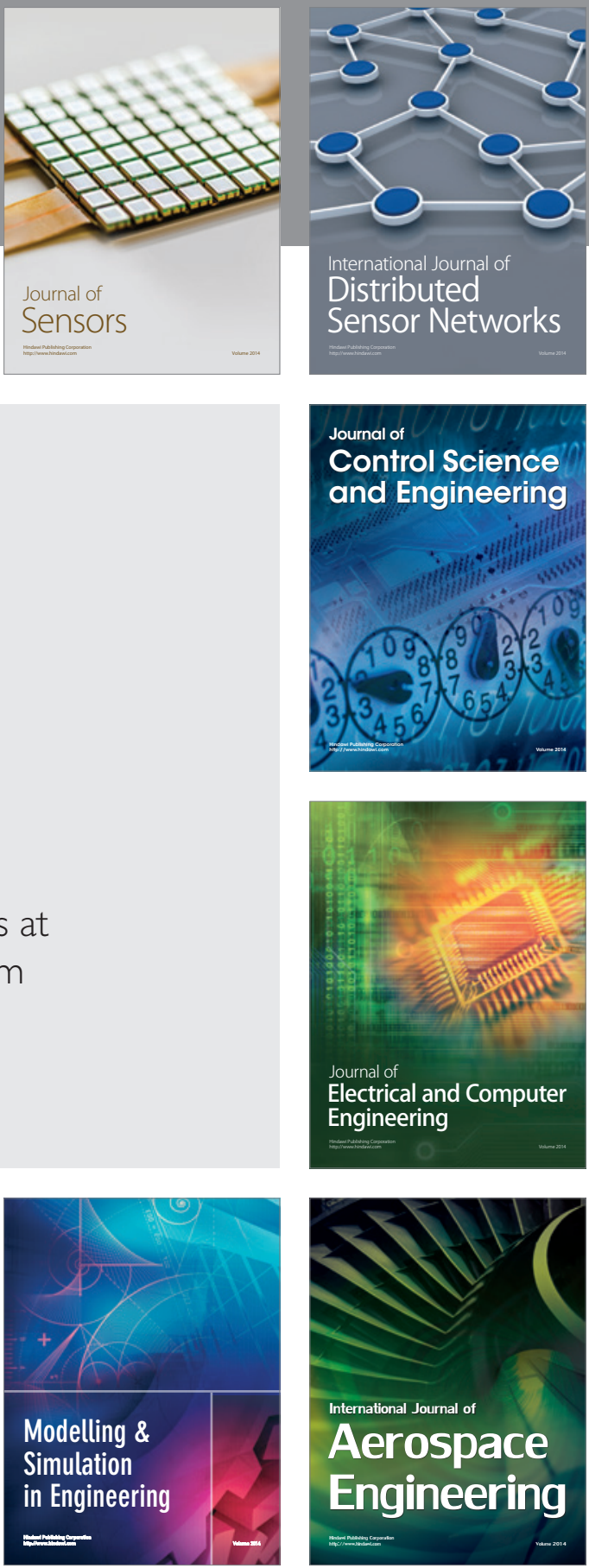

Journal of

Control Science

and Engineering
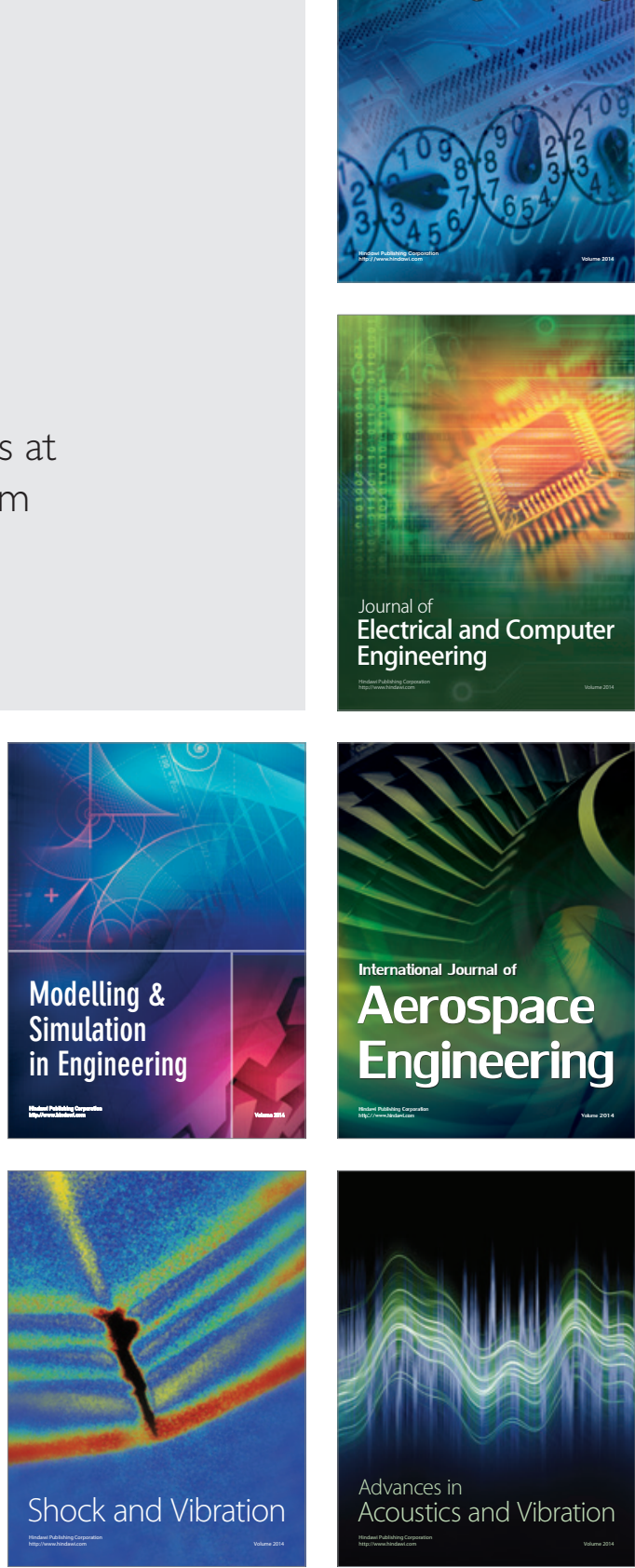